\title{
The Art of Creative Thinking as a Basis of Modern Labor Philosophy
}

\author{
Irina Lyskova \\ The Economics and Management Department \\ The Komi Republic Academy of State Service and Administration \\ Syktyvkar, Russia \\ E-mail: IrinaLyskova@mail.ru
}

\begin{abstract}
The article studies the main tasks of quality management and the importance of rational approaches to the human resources management in an organization. The article provides the general characteristics of creative thinking and creative processes. Moreover, it emphasizes the importance of intellectual technologies in the aspect of quality management, reveals the essence of creativity as an intellectual technology of the model of the modern human resources quality and strategic development of an organization.
\end{abstract}

Keywords-quality management; human resources quality; intellectual technologies of quality management; innovation; creativity; labor motivation; system thinking; strategic thinking; creative thinking

\section{INTRODUCTION}

Creativity is considered an exceptionally important characteristic feature of modern employees' professional activity. Creativity can be understood as a level of creative talent, skills, which constitutes a stable characteristic of a personality [1]. The terms 'creation' and 'creativity' are related in meaning to the term 'invention' from the Latin 'invention' (to compose, create).

In Russian, the term "creativity" was widely used to characterize the essence of the process and the result of creating something new. Taking into account the fact that life and nature themselves are the source and the result of creative efforts, the term "creativity" was applied to characterize human activity, in particular. Unquestionably, creativity is originally characterized as a mental process. It is expressed in "the embodiment, reproduction or combination of the data of our consciousness in a (relatively) new and original form in the field of abstract thought, artistic and practical activity" [2]. Accordingly, the following types of creativity are singled out: scientific, poetic, musical, visual, theatrical, military, administrative (art of management), etc. It is vital to note that in science there is a special branch of philosophy - aesthetics, that studies various aspects of art and beauty. Art is characterized as "science, knowledge, skills", "ability, developed by skills or learning", "mastership that requires great skills and taste" [3].

Despite the fact that attempts to explore the philosophical, aesthetic, psychological and practical nature of creativity have been going on for several millennia, from the time of the great philosophers of antiquity: Aristotle, Plato, Cicero; the creative process still remains one of the most interesting, unique, mysterious and unpredictable phenomena inherent to human activity. Undoubtedly, creativity is the product of human thinking activity, and the ability to think is inevitably linked to the intelligence level. As far back as Aristotle, three basic properties of intelligence were distinguished: contemplative, active and creative. Nevertheless, the nature of creativity, as well as the sources of creative inspiration, have not been studied thoroughly. Taking into account the process of personality evolution, based on continuous intellectual development inter alia, we assume the possibility of improving the human abilities for creative thinking. From our point of view, at the very least, the art of creative thinking includes a developed ability of an individual to system, process and problem thinking [4] [5] [6].

It is important to note that creative thought can be both a product of a conscious, rational property, and the result of an unconscious, irrational, intuitive manifestation. Moreover, the ability to create, the creative potential of an individual is associated not only with the intellect, but also with the practical activities of a person, professional activity included. Obviously, in conditions of market economy development, increasing competition, the need for continuous updates of production processes, the introduction of new technologies, those people have an exceptionally important role, who have a strong potential to develop and implement innovations, possess a high level of motivation for individual and team work, ambitions for professional development and professional competencies improvement. Modern economy requires new approaches to the development and implementation of modern labor philosophy, according to which labor itself can become a source of creativity, creative inspiration, satisfaction of high personal needs, aesthetic pleasure, joy and even happiness.

\section{THE SCIENTIFIC BASES OF INTELLECTUAL SOCIETY AND PERSONALITY PROGRESS (HISTORICAL CONTEXT)}

Reflections on the essence of creativity turn us to the problems of cultural and social history, the evolution of the scientific thought of Western Europe. The idea of mental progress, especially of the second half of the XIX century, is 
gaining exceptional significance in this context. In the period mentioned, there were three main scientific concepts that formed the basis of many areas of knowledge. Saying this, we mean the scientific ideas by A. Comte, H. Spencer and Ch. Darwin. Later, the theory of "economic materialism" by $\mathrm{K}$. Marx joined the list of the most influential concepts on public consciousness. With full certainty, it can be asserted that these concepts laid the foundation for the modern behavioral economics, economic psychology, and cognitive science formation and development.

N.I. Kareev (1850-1931), a famous philosopher, historian, founder of Russian sociology, paid great attention to the history of scientific thought in the second half of the 19th century. A profound analysis of the views of A. Comte, $\mathrm{H}$. Spencer, and Ch. Darwin enabled him to conclude that there was a close connection between the three doctrines mentioned. In particular, N.I. Kareev stressed that "... in all three directions, the idea of development has a very prominent, if not to say, primary position". He noted that these theories destroyed the idea of the immutability of natural properties of a human. Then mental progress was inevitably linked to the idea of improving the very abilities of a person, as well as the moral enhancement of an individual [7] [8].

Let us dwell on the most significant thoughts of the above-mentioned theories. In the aspect of the idea of creativity, the views of A. Comte and H. Spencer are of particular interest, from our point of view. In the system of philosophical and sociological views by A. Comte (17981857), the positions inextricably linked with the process of formation of the system of human knowledge need to be singled out. Firstly, this is the doctrine of "three different theoretical states" or stages through which the ideas about the world around, as well as about a man themselves gradually pass to form: the state of theological way of thinking; metaphysical state or "abstract way of thinking"; the state is positive or "scientific thinking". The society has been developing following the similar way. As it is known, A. Comte received worldwide recognition as the founder of sociology, which he divided into social statics and social dynamics. To the first category, he ascribed politics, jurisprudence, political economy, which regard society as something stable. The idea of development was closely connected with the process of cultural and social life of humankind. The main principle of the social dynamics by A. Comte was the law of mental development, fixed in the above formula of three consecutive stages of the world perception. Recognizing the complexity of social processes studying and understanding, A. Comte defined the need for the establishment of so-called "social physics" (sociology), which would set the grounds for a new philosophical outlook and social reconstruction.

Analyzing A. Comte's views, N.I. Kareev focuses on changing the approaches to understanding the essence of the idea of progress. First, N.I. Kareev noted that the "idea of progress" was replaced by the concept of "evolution." The Russian scientist critically characterizes the opinion of A. Comte on the possibility of considering all social physics, "never using the words perfection, enhancement, replacing them with the term development, which is devoid of moral evaluation of a person. N.I. Kareev highly appreciated the role of A. Comte in the process of new science formation and understanding the essence of a human. The development of a scientific knowledge system was recognized as an inalienable merit of A. Comte, it took shape of a classification of sciences, with a certain order in decreasing similarity and increasing complexity: mathematics, astronomy, physics, chemistry, physiology (biology) and social physics or sociology.

These questions draws us to one of the bright followers of positivism and representatives of the organic school of sociology, H. Spencer (1820 -1903). Sharing the statements by A. Comte on the proximity of sociology and biology, $\mathrm{H}$. Spencer in his multi-volume work "The System of Synthetic Philosophy" emphasizes the biological analogy, characterizes society as a sort of a higher-order organism that develops according to the laws of evolution. H. Spencer introduced the scientific term "natural selection" to justify the law of survival in a society where the one who adapts to life most, survives.

The pedagogical treatise by H. Spencer "Education of the Mental, Moral and Physical" (1861) is of particular interest. According to $\mathrm{H}$. Spencer's convictions, organizing educational activity should be based on the principle of the usefulness of knowledge and its conformity to certain types of human activity, ensuring the self-preservation of a man. Accordingly, the knowledge in the field of physiology, hygiene, physical education can be found useful. Adapting to the sphere of industry and trade requires from a person the knowledge of arithmetic, geometry, mechanics, physics, chemistry, astronomy, geology, biology, and social science. At the same time, in order to procreate and raise offspring, the knowledge in the field of physiology, pedagogy, and psychology is extremely necessary. In social terms, the history of society, as well as aesthetic awareness, that is, acquaintance with art, painting, music, poetry, with a view to the reasonable organization of leisure of a person, are especially important. H. Spencer characterized education and upbringing as a means of survival, ensuring a person's readiness for practical life, taking into account the external conditions of the social environment.

N.I. Kareev payed his attention to the significance of certain statements of $H$. Spencer's evolutionism, due to which the idea of progress received a new understanding. First of all, evolutionism emphasized the link between the historical process and the process of nature development, characterized by constant changes. Secondly, the new doctrine drew attention to the process of changing the internal qualities of a person. Thirdly, this theory was filled with profound philosophical ideas about the role of a person in history, which could not be reduced to a "simple contemplation of evolution". Nevertheless, N.I. Kareev considered the organic theory by $\mathrm{H}$. Spencer to be very controversial; he wrote: "... This theory helps us to understand the nature of society in some way, but in most cases not on the question of what a society is, but on the question of what is not a society and what cannot be a society" [7] [8]. 
As the history of scientific thought attests, mental progress, determined by the "successes of the human mind," is not subject to any doubt. However, the main problem was and is that the mental progress of the humankind does not guarantee the moral progress. Taking into account the current situation, it is difficult to disagree with this idea.

\section{THE ESSENCE OF THE MODERn LABOR PHILOSOPHY}

Current trends in social and economic development justify the need for systematic qualitative changes in the process of organizing labor in order to improve the competitiveness of the national economy as a whole, and organization, in particular, and to ensure a transition to an innovative model of organizational development, the formation of modern culture and the philosophy of labor. The possibility of qualitative changes in the system of modern economy largely depends on the quality of human resources, the spiritual culture of an individual and a team.

The knowledge in the aspect of organizational development can be characterized as a set of personal abilities, general cultural and professional competencies of an employee, acquired in the course of professional activity. The system of organizational knowledge is formed by a combination of: an organization's development strategy; scientific foundations of production organization; practical application of scientific knowledge in a specific field of professional activity; organizational culture as a powerful factor of effective production and adaptation to the conditions of a market economy. Accordingly, the concept of knowledge management is based on the transformation of individual knowledge and competences of employees into the intellectual potential and intellectual capital of an organization. All this forms the basis for the strategy and tactics of organization development, modern philosophy of organization, collective and personal philosophy of labor.

The process of consolidation of modern labor philosophy in the minds of employees is subject to the influence of external and internal factors that promote or hinder the effectiveness of organizational change. Particularly difficult is the change in consciousness, the way of thinking of employees and leaders of an organization, contributing to the continuous motivation of professional development and a creative approach to work. In the process of the modern philosophy of labor formation [9]. It is vital to consolidate the basic principles of development: continuous improvement; responsible and conscientious attitude to the cause and responsibilities; meeting the continuously rising standards, business rules and regulations; interaction with customers and partners; principles of organization effectiveness, such as creativity, the desire to innovate, flexibility and adaptability. All this is related to the qualitative characteristics of professional managerial culture [10].

The innovative development of an organization includes developing a knowledge management strategy; collecting the successful companies' experience; improving organizational culture system in terms of recognizing the value of knowledge; continuous intellectual and moral progress of an individual; forming an innovative model of an employee's behavior, especially in terms of the initiative in the field of professional activity, the development of professional competences, self-education, etc. It is indisputable that it is the modern philosophy of organizations, based on a modern work philosophy that is designed to ensure economic growth and quality of life of a modern society.

The essence of modern organization philosophy is characterized as a set of internal organizational principles, ethical and administrative norms, rules and requirements for behavior and interactions in an organization and is embodied in the process of achieving the set goals of an organization [11]. The philosophy of an organization combines the mission, strategy, quality policy, personnel policy, social policy, professional ethics, etc., while the structure of an organization's philosophy reflects the goals and objectives of the organization; declaration of employee rights; requirements for the behavior of employees; business and moral qualities that employees have to possess; working conditions, workplace and working environment; system of payment and labor evaluation; system of social benefits and guarantees; personal interests and hobbies of employees, etc. Theoretical and practical aspects of collective labor philosophy should not contradict the existing legislation, violate the rights and social guarantees of employees. The practical embodiment of the organization's philosophy is connected with the realization of the personal philosophy of labor.

In terms of understanding personal effectiveness, including the basic principles of modern labor philosophy the way of personal philosophy (mission) development and implementation acquired widespread recognition. Due to this system, a great number of people managed to achieve high results in all the aspects of life. Stephen R. Covey emphasized the importance of the following areas of work on oneself:

- Be proactive (do not depend on circumstances, create your own destiny yourself);

- Begin with the End in Mind (start a business with the image of its ultimate goal);

- Put First Things First (maintain priority in your affairs, start with the most important things);

- Think Win-Win (strive for the common benefit);

- Seek First to Understand, Then to Be Understood;

- Synergize;

- "Sharpen the saw" (constantly improve) [12].

\section{Creative Thinking And Creative Process}

Creativity, as a person's ability to think and act in a nonstandard, original way is more than ever in high demand in the sphere of professional activity. The creative potential of an individual is a combination of abilities and resources that ensure the realization of an individual creative approach in the process of solving professional and managerial tasks [13]. 
The process of personality development is largely determined by the specifics of intellectual work, the ability of a person to generate new ideas and original thoughts, set goals, and understand rational and effective ways to achieve them. One of the significant characteristics of professional development is the ability of a person to analyze, systematize, structure information, move from the reproductive thinking model to the innovative one, to the most efficient ways for solving professional problems. Thus, the uniqueness of the intellectual creative activity of a person with a high degree of freedom, initiative, self-motivation for work, selforganization, self-control, awareness of personal responsibility for the process and the result of labor represent the basis of modern business processes.

It is the creative potential of the employee's personality that is an indispensable condition for the development of any organization. Strategic management considers creativity not only as an object of management, but also as a means of increasing efficiency, a source of innovation, development of employees' professionalism. It is important to note that creativity to a grate extend conditioned by the intellectual abilities of an individual. The fluency of thinking (the number of ideas that arise over a given period of time, the flexibility of thinking (the ability to switch from one idea to another), the originality of thinking (the ability to generate non-standard thoughts), curiosity (the special interest to certain questions) can be pointed out as the most significant abilities of a person, ensuring a high level of art of thinking creatively.

The concept of creative thinking can be built on the basis of a multidimensional structure of a personality's intellect. The search for sources for creativity at the individual and group level is inextricably linked with the structure of the human intellect. Physical intelligence reflects the essence of psychophysiological abilities and the foundations of professional activity (the quality of work, the regime of work and leisure, sanitary and hygienic standards of work, working conditions and environment, health of employees, physical and mental well-being, level of stress-resistance, etc.). Mental intelligence, characterizes the cognitive abilities of an individual, the level of education and professional qualifications, the level of cognitive culture of an individual, intellectual abilities (logical, analytical, critical, creative, strategic, systemic, process, problematic thinking, etc., which form the basis of a rational way of learning the world), as a whole. Spiritual intellect fixes the foundations of the spiritual and moral culture of a person and the system of personal values, actualizes the tasks of managing needs and the importance of personality education. Emotional intelligence combines a set of personal and social skills of a person, fully disclosed in the field of professional activity [14] [15] [16].

The art of creative thinking is a multifaceted and debatable topic. There cannot be patterns and algorithms of actions given, that guarantee generating creative ideas, development of unique abilities, talent, and professional skills. The quality of the creative process, both on the individual and group level, is determined by a combination of various factors of internal and external properties.
Nevertheless, the main source of creativity to be recognized is the culture of an individual and the culture of an organization, and the quality of a personality (knowledge, skills, qualifications, goals, values, needs, etc.), the quality of business processes (goals and values of an organization, leadership style, team cohesiveness, employees' involvement and dedication, etc.), in particular . Professional and life experience, knowledge, information, time, technology, finance are the important conditions for manifesting the creativity of an individual and organization.

The creative process is characterized by a special psychophysiological, psycho-emotional state of a person. The famous American psychologist M. Csikzentmihalyi calls this state a "flow". In his opinion, the most characteristic features of this state of perfect joy are:

- Clarity of tasks;

- Correspondence of individual abilities and human skills to the complexity of tasks;

- Achieving a state of awareness and mental concentration, focus on specific actions and tasks;

- A sense of control over the situation;

- A high level of inspiration and commitment to something great;

- Changing the sense of perception of time (usually its acceleration), etc. [17 [18].

The author of the "flow" concept, the psychology of optimal experience, emphasizes that in this state, a person, even when solving the most difficult problems, feels happier, more active, vigorous, focused, and also creative. However, in the author's opinion, there is a striking paradox. The process of solving complex problems, requiring the activation of skills and abilities, gives a person pleasure and joy. In his spare time, when a person's abilities are not involved, a person often suffers from various negative experiences and emotions. At the same time, most people prefer to work less and rest more. This problem is explained by the presence of stereotypes that labor cannot be joy, weak motivation for work, routine, conflicts, emotional burnout, stress, etc. The main conclusion is that it is necessary to pay attention not only to the organization of work, but also to leisure. The 'flow' model is based on the awareness of the events experienced by a person. Consciousness is "expediently ordered information" that forms a system of life values and human goals.

The concept of productivity by C. Bailey can be considered of the same interest. He offers a special rational system built on improving the mental approaches to time management, attention and energy. In the core of this model is an adequate structuring of thinking and activity, thereby ensuring the control of consciousness over the intellectual, psychophysiological, social, and other processes in which a person is involved. It is interesting that the author himself experienced the effect of the well-known methods of personal effectiveness improving and was convinced that productivity consists of three components: time, attention 
and energy. He stressed that in the economy of knowledge those achieve outstanding successes, who will learn to combine the components most effectively, that is, consciously [19].

Original techniques and ways of developing creative thinking have been offered by a famous English artist, designer, educator and business consultant R. Judkins [20]. With the help of simple but effective tools, people of different occupation can develop their creative abilities and reveal the potential for creative growth in solving every day and professional tasks. R. Judkins notes that each person is unique, so it is important to understand and your life principles and values. According to the author, it makes sense to deal only with something that makes sense. Almost everyone from nature has the high level of imagination, intuition and intellect, but many people simply do not learn to use this wealth, and just waste it. The desire for selfdevelopment, self-improvement provides the opportunity for creative abilities development, and the freedom of an individual is an indispensable condition for such development. Creative thinking, according to the expert, is a combination of vision, knowledge and image. Creativity is not a skills demonstration, it is a sincere desire to understand and express ideas in one area or another. "A great idea can fill us with energy and excitement," that is, it immerses us in a state of flow, a state of full involvement and activity. In administrative terms, productivity directly depends on the employees' ability to be involved in the decision-making process. R. Judkins notes that "creativity is very like the work of a miner; you need to dig deeper, discovering and studying yourself".

\section{CONCLUSION}

Thus, the current situation justifies the importance of continuous personal development, intellectual technologies improvement as the basis for the formation of a system of human resources quality management and modern labor philosophy in an organization. Nowadays, the value of the intellectual potential of employees in solving professional problems is widely recognized. Revealing the essence of creative thinking in a personality intelligence system provides the understanding of the scientific and practical foundations for creating the necessary conditions to promote creativity development on an individual and team level [21] [22] [23].

\section{REFERENCES}

[1] A.O. Blinov, O.S. Rudakova, The research of the creative process nature. Herald of Ivanovo State University: Economics. 2012. No. 2. pp. 6-13.

[2] F.D. Batyushkov, Creation. Encyclopedic dictionary of F.A. Brockhaus and I.A. Efron. Vol. XXXIIA (64). Saint Petersburg, 1901. pp. 729-730.

[3] V.I. Dal, Defining dictionary of Great Russian language. Vol. 2. Saint Petersburg-Moscow. 1881. P. 51.

[4] I. Lyskova, The Main Paradigms of Creative Management in the Aspect of Modern Cognitive Economy // Advances in Social Science, Education and Humanities Research. Vol. 103 / International Conference on Culture, Education and Financial Development of
Modern Society (ICCESE 2017) Atlantis Press, 2017, pp. 644-649 // https:/www.atlantis-press.com/php/pub.php?publication=iccse-2017

[5] I. Lyskova, Mental Reengineering as an Intellectual Technology of a Human Resources Quality Management in a Modern Organization // Advances in Social Science, Education and Humanities Research. Vol. 205 / The 2nd International Conference on Culture, Education and Economic Development of Modern Society (ICCESE 2018) Atlantis Press, 2018, pp. 903-906 // https:/ proceedings/iccese-18/25894060

[6] I.E. Lyskova, Intellectual Technologies as the Basis of the Innovative Model of Management of Quality of Human Resources of the organization. National Concepts of Quality: the Integration of Education, Science and Business. The Collection of Articles of the VIII International Research and Practice Conference. Saint Petersburg, 2017, pp. 99-102.

[7] I.E. Lyskova, The philosophic and sociological roots of selfmanagement. In the World of Scientific Discoveries. Human and Social Sciences. Krasnoyarsk: Publishing House Science and innovation Center. 2014, No. 7.2 (55), pp. 757-776.

[8] I.E. Lyskova, Self-education as an intellectual technology of rapid development of a personality's potential in conditions of global economy (To the question of the history of self-management. Global Economy in XXI Century: Dialectics of Confrontation and Solidarity. London: LSP. 2018, pp. 444-458.

[9] I. S. Adizes, Mastering Change. The Power of Mutual Trust and Respect in Personal Life, Family Life, Business and Society. Moscow. Mann, Ivanov and Ferber. 2016. - 368 p.

[10] I.E. Lyskova, The problems of human capital management in the aspect of modern knowledge economy. Journal of economy and entrepreneurship. 2017. No. 9 (P. 4) (84-4), pp. 641-645.

[11] I. Lyskova, Moral concepts of modern business processes // International Conference on Judicial, Administrative and Humanitarian Problems of State Structures and Economical Subjects (JAHP 2016) // Atlantis Press, 2016. Pp. 37-41 // www.atlantispress.com/php/pub.php?publication=jahp-16.

[12] S.R. Covey, The 7 Habits of Highly Effective People. Restoring the Character Ethics. Moscow: Alpina Publisher. 2015. - 396 p.

[13] I.E. Lyskova, Cognitive and Creative Management as a Basis of Innovative Development of Modern Organization. Public and Private Finances in the Innovative Economy. The Collection of Articles of the International Research and Practice Internet Conference. Plechanov Russian University of Economics. Moscow. 2017, pp. 123 132.

[14] S.R. Covey, The 8th habit. From effectiveness to greatness. 9 ed. Moscow: Alpina Publisher.2014, 408 p.

[15] D. Goleman, Emotional Intelligence. Why It Can Matter More Than IQ. Moscow. Mann, Ivanov and Ferber. 2017. - 544 p.

[16] D. Goleman, R. Boyatzis, A. McKee, Primal Leadership. Learning to Lead with Emotional Intelligence. Moscow, Alpina Publisher. 2017. $301 \mathrm{p}$.

[17] M. Csikszentmihalyi, Flow. The psychology of optimal experience. Moscow: Smysl, Alpina non-fiction. 2015, 461 p.

[18] M. Csikszentmihalyi, The Evolving Self. A Psychology for the Third Millennium. Moscow: Alpina non-fikshn. 2013,-420 p.

[19] C. Bailey. The Productivity Project. Accomplishing More by Managing Your Time, Attention, and Energy Better. Moscow: Alpina Pablisher.2017, - 300 p.

[20] R. Judkins, The Art of Creative Thinking. 2016. Moscow: Azbuka Biznes, Azbuka-Attikus. -432 p.

[21] J. O'Connor, I. McDermott, The art of systems thinking. Essential skills for creativity and problem solving. Moscow: Alpina Publisher. $2015,-256 \mathrm{p}$.

[22] D. Sherwood, Seeing the forest for the trees. A Manager's Guide to Applying Systems Thinking. Moscow: Alpina Publisher. 2016, - 300 p.

[23] I.E. Lyskova, The Role of the Corporate Culture in the Adaptation of the Society to the New Challenges of the Global Economy. Global Economy in XXI Century: Dialectics of Confrontation and Solidarity. London: LSP. 2018, pp. 420-431. 